\title{
Poly(alkylene 2,5-furandicarboxylate)s (PEF and PBF) by Ring Opening Polymerization
}

\author{
Juan Carlos Morales-Huerta, Antxon Martínez de llarduya \\ and Sebastián Muñoz-Guerra* \\ Department d'Enginyeria Química, Universitat Politècnica de Catalunya, ETSEIB, \\ Diagonal 647,8028 Barcelona, Spain
}

\begin{abstract}
The preparation of cyclic ethylene and butylene 2,5-furandicarboxylate oligoesters and their conversion to furan-based polyesters poly(ethylene furanoate) (PEF) and poly(butylene furanoate) (PBF) by ring-opening polymerization (ROP) are described. The cyclic oligoesters were obtained in high yields by both high dilution condensation and thermal cyclodepolymerization methods, and they consisted of mixtures of small size species. Cyclic dimer, trimer and tetramer oligoesters were isolated by semipreparative chromatography and found to be crystalline compounds melting within the $140-200{ }^{\circ} \mathrm{C}$ range. ROP catalyzed by $\mathrm{Sn}(\mathrm{Oct})_{2}$ of both mixtures and individual species afforded PEF and PBF with weight-average molecular weights between 50,000 and $60,000 \mathrm{~g} \cdot \mathrm{mol}^{-1}$. Polymerization rate was found to be higher for butylene than for ethylene cyclic oligofuranoates, and also to increase slightly as cycle size decreased. The thermal properties of PEF and PBF prepared by ROP were in full agreement with those reported for these polyesters obtained by melt polycondensation.
\end{abstract}

Keywords: polyfuranoates, ring opening polymerization, bio-based aromatic polyesters

\section{Introduction}

2,5-Furandicarboxylic acid (FDCA) is a sugar-based compound that has attained high notoriety in these last years due to its great potential as a renewable platform for the synthesis of a wide variety of chemicals, ${ }^{1-3}$ and in particular of polymers produced by polycondensation. ${ }^{4-5}$ The outstanding relevance of FDCA to the development of new bio-based polyesters has been updated in an excellent review published recently by Sousa et al. ${ }^{6}$ The chemical structure, thermal stability and aromatic nature of FDCA are features that make this diacid specially suitable for replacing terephthalic acid in the preparation of the important engineering thermoplastics poly(ethylene terephthalate) (PET) and poly(butylene terephthalate) (PBT) (Scheme 1). In fact, most of efforts made up to date on the development of FDCA as monomer have been addressed to the synthesis of poly(ethylene 2,5- 
furandicarboxylate) (PEF) and poly(butylene 2,5-furandicarboxylate) (PBF) homopolyesters ${ }^{7-9}$ and copolyesters, ${ }^{10-14}$ and Avantium in Netherlands started in 2010 the industrial production of PEF on multi-ton scale for fibers and packaging. The aliphatic-furanic polyesters based on FDCA have been shown to have enhanced thermo-mechanical ${ }^{11,15-17}$ and biodegradable ${ }^{18-19}$ properties over existing terephthalate polyesters.

Both PEF and PBF are usually synthesized from either pristine $\mathrm{FDCA}^{7-9}$ or its dimethyl ester, ${ }^{15}$ by polycondensation in the melt through a two-steps process. Organometallic catalysts, temperatures well above the $T_{m}$ of the resulting polyfuranoate, and periods of time of hours to days are required to attain high reaction extents. The main processing difficult arises from the high melt viscosity achieved by the reaction mixture that severely hampers mass transfer and makes therefore difficult to remove the volatile condensation products. ${ }^{20}$ Post-polycondensation in the solid state is performed as a third-step in order to increase further the molecular weight. ${ }^{14,15}$ The severe conditions applied in the polycondensation usually imply some discoloration and eventual generation of minor amounts of secondary products.

Ring opening polymerization (ROP) is a well-stablished technique that has been extensively used for the polymerization of a wide variety of cyclic compounds and in particular of cyclic oligoesters. ${ }^{21}$ The relatively soft reaction conditions applied in this method makes feasible to synthesize high molecular weight polymers in good yields without perceivable chemical alteration of the product. Specific advantages of ROP are a high polymerization rate, the absence of reaction coproducts, and the low viscosity retained by the reaction until high conversions are attained. Consequently the formation of secondary by-products is almost insignificant, the remaining monomer can be easily removed, and discoloration is minimized. Both $\mathrm{PET}^{22-24}$ and $\mathrm{PBT}^{22,25,26}$ have been successfully synthesized by ROP of cyclic oligo(alkylene terephthalate)s applying temperatures between $200{ }^{\circ} \mathrm{C}$ and $300{ }^{\circ} \mathrm{C}$ and times of minutes. The oligoesters required for these syntheses were furnished either by condensation of terephthaloyl 
dichloride with diols in highly diluted solution (HDC, high dilution condensation) or by thermal depolymerization in solution of the corresponding polyester (CD, cyclodepolymerization) methods. The CD method is particularly interesting with regards to the potential recycling of the polyester. ${ }^{27}$

In the present paper we wish to report on the preparation of high molecular weight PEF and PBF by ROP of the corresponding cyclic oligo(alkylene 2,5furandicarboxylate)s. Both the HDC and CD methods have been here applied for the synthesis of these cyclic oligoesters, and the influence of cycle size on polymerization rate has been investigated. The synthetic pathway followed in this work is depicted in Scheme 2. The characteristics of the resulting PEF and PBF are compared with those reported for the same polyesters obtained by polycondensation. A paper reporting the preparation of PBF by ROP came out just in these last days. In such work polymerization was accomplished using a mixture of cyclic butylene furanoates prepared by HDC to obtain a PBF with moderate molecular weight. ${ }^{28}$

\section{EXPERIMENTAL SECTION}

Materials. 2,5-Furan dicarboxylic acid (FDCA, >99\% purity) was a donation of Drs. K Wilsens and B. Noordover (Technische Universiteit, of Eindhoven, NL). Other reagents as 1,4-butanediol (BD, 99\%), ethylene glycol (EG, 99\%) and thionyl chloride $\left(\mathrm{SOCl}_{2}, 99 \%\right)$, as well as catalysts dibutyltin(IV) oxide (DBTO, 98\%), diazabicyclo[2.2.2] octane (DABCO, 99\%) and tin(II) ethylhexanoate (Sn(Oct) $2,99 \%)$, were purchased from Sigma-Aldrich Co. Antioxidants Irganox 1010 and Irgafos 126 used for polycondensation reactions were gifts from BASF. Solvents used for reaction, isolation and purification were of high-purity grade and used as received except dichloromethane (DCM), tetrahydrofurane (THF) and dichlorobenzene (DCB) that were dried on $3 \AA$-molecular sieves. DABCO catalyst was purified by sublimation. 
Measurements. ${ }^{1} \mathrm{H}$ and ${ }^{13} \mathrm{C}$ NMR spectra were recorded on a Bruker AMX-300 spectrometer at $25^{\circ} \mathrm{C}$, operating at 300.1 and $75.5 \mathrm{MHz}$, respectively. Compounds were dissolved in deuterated chloroform $\left(\mathrm{CDCl}_{3}\right)$ or a mixture of trifluoroacetic acid (TFA) and $\mathrm{CDCl}_{3}$, and spectra were internally referenced to tetramethylsilane (TMS). About 10 and $50 \mathrm{mg}$ of sample in $1 \mathrm{~mL}$ of solvent were used for ${ }^{1} \mathrm{H}$ and ${ }^{13} \mathrm{C} \mathrm{NMR}$, respectively. Sixty-four scans were recorded for ${ }^{1} \mathrm{H}$ and between 1,000 and 10,000 scans for ${ }^{13} \mathrm{C}$ NMR. Molecular weight analysis was performed by GPC on a Waters equipment provided with RI and UV detectors. $100 \mu \mathrm{L}$ of $0.1 \%(\mathrm{w} / \mathrm{v})$ sample solution was injected and chromatographed with a flow of $0.5 \mathrm{~mL} \cdot \mathrm{min}^{-1}$. HR5E and HR2 Waters linear Styragel columns $\left(7.8 \mathrm{~mm} \times 300 \mathrm{~mm}\right.$, pore size $\left.10^{3}-10^{4} \AA\right)$ packed with crosslinked polystyrene and protected with a precolumn were used. Molar mass average and distributions were calculated against PMMA standards. High-performance liquid chromatography (HPLC) analysis was performed at $25{ }^{\circ} \mathrm{C}$ in a Waters apparatus equipped with a UV detector of Applied Biosystems, operating at $254 \mathrm{~nm}$ wavelength, and a Scharlau Science column (Si60, $5 \mu \mathrm{m} ; 250 \times 4.6 \mathrm{~mm}$ ). Cyclic oligomers $(1 \mathrm{mg})$ were dissolved in $\mathrm{CHCl}_{3}(1 \mathrm{~mL})$ and eluted with hexane/1,4-dioxane $70 / 30(\mathrm{v} / \mathrm{v})$ at a flow rate of $1.0 \mathrm{~mL} \cdot \mathrm{min}^{-1}$. Semipreparative HPLC was performed using a Scharlau Science column (Si60, $100 \mu \mathrm{m} \times 19 \mathrm{~mm}$ ) with the cyclic oligomers sample $(35 \mathrm{mg})$ dissolved in $\mathrm{CHCl}_{3}(3 \mathrm{~mL})$ and eluted with a mixture of hexane/1,4dioxane $70 / 30(\mathrm{v} / \mathrm{v})$ with a flow rate of $17 \mathrm{~mL} \cdot \mathrm{min}^{-1}$. Individual fractions were collected with an UV-monitored Waters Fraction Collector III.

Matrix-assisted laser desorption/ionization time of flight (MALDI-ToF) mass spectra were recorded in a 4700 Proteomics Analyser instrument of Applied Biosystems (Proteomics Platform of Barcelona Science Park, University of Barcelona). Spectra acquisition was performed in the MS reflector positive-ion mode. About $0.1 \mathrm{mg}$ of sample was dissolved in $50 \mu \mathrm{L}$ of DCM and $2 \mu \mathrm{L}$ of this solution were mixed with an equal volume of DCM solution of anthracene $\left(10 \mathrm{mg} \cdot \mathrm{mL}^{-1}\right)$, and the 
mixture left to evaporate to dryness onto the stainless steel plate of the analyser. The residue was then covered with $2 \mu \mathrm{L}$ of a solution of 2,5-dihydroxibenzoic acid in acetonitrile/ $\mathrm{H}_{2} \mathrm{O}(1 / 1)$ containing $0.1 \%$ TFA, and the mixture was left to dry prior to exposition to the laser beam.

Thermogravimetric analysis (TGA) of cyclic oligomers and polymers was performed on a Mettler-Toledo TGA/DSC 1 Star System under a nitrogen flow of 20 $\mathrm{mL} \cdot \mathrm{min}^{-1}$ at a heating rate of $10{ }^{\circ} \mathrm{C} \cdot \mathrm{min}^{-1}$ and within a temperature range of $30-700$ ${ }^{\circ} \mathrm{C}$. The non-destructive thermal behaviour was examined by differential scanning calorimetry (DSC) within the $30-200{ }^{\circ} \mathrm{C}$ range using a Perking-Elmer Pyris apparatus. Thermograms were obtained from 4-6 mg samples at heating and cooling rates of 10 ${ }^{\circ} \mathrm{C} \cdot \mathrm{min}^{-1}$ under a nitrogen flow of $20 \mathrm{~mL} \cdot \mathrm{min}^{-1}$. Indium and zinc were used as standards for temperature and enthalpy calibration, respectively. The glass transition temperature $\left(T_{g}\right)$ was taken as the inflection point of the heating traces recorded at 20 ${ }^{\circ} \mathrm{C} \cdot \mathrm{min}^{-1}$ from melt-quenched samples, and the melting temperature $\left(T_{m}\right)$ was taken as the maximum of the endothermic peak appearing on the heating traces recorded from samples crystallized from the melt. X-rays diffraction was made in the Synchrotron ALBA facility (Barcelona) using powder samples which were irradiated with a bean energy corresponding to $0.1 \mathrm{~nm}$ wavelength.

Synthesis of cyclic oligomers by pseudo-high dilution cyclization (HDC). 2,5Furandicarbonyl dichloride $\left(\mathrm{FDCA}-\mathrm{Cl}_{2}\right)$ was prepared according to the method reported by Gomes et al. ${ }^{7}$ with minor modifications. In brief, $6.4 \mathrm{mmol}(1 \mathrm{~g})$ of FDCA was made to react with $2 \mathrm{~mL}$ of $\mathrm{SOCl}_{2}$ in the presence of $10 \mu \mathrm{L}$ of dimethyl formamide (DMF) for 8 hours under reflux. After removing the excess of $\mathrm{SOCl}_{2}$ the residual product was purified by high vacuum sublimation. $\mathrm{FDCA}-\mathrm{Cl}_{2}$ was obtained as a white powder in $90 \%$ yield and m.p. $=79^{\circ} \mathrm{C} .{ }^{1} \mathrm{H}$ NMR $\left(\delta \mathrm{ppm}, \mathrm{CDCl}_{3}, 300 \mathrm{MHz}\right)$ : 7.60 (s, 2H). ${ }^{13} \mathrm{C}$ NMR ( $\left.\delta \mathrm{ppm}, \mathrm{CDCl}_{3}, 75.5 \mathrm{MHz}\right): 155.9,149.4,123.3$. These NMR spectra are accessible in the SI file (Figure SI-1). 
Cyclic oligomers $c(B F)_{n}$ and $c(E F)_{n}$ were synthesized by applying the method reported by Brunelle et al. ${ }^{22}$ for the synthesis of oligo(alkylene phthalates).Error! Bookmark not defined. A three-necked round bottom flask was charged with $25 \mathrm{~mL}$ of $\mathrm{DCM}$ and cooled to $0^{\circ} \mathrm{C}$, and then $12.5 \mathrm{mmol}(1.40 \mathrm{~g})$ of DABCO were added under stirring. $5 \mathrm{mmol}(0.96 \mathrm{~g})$ of FDCA-Cl ${ }_{2}$ in $10 \mathrm{~mL}$ of DCM and $5 \mathrm{mmol}(0.46 \mathrm{~g})$ of BD or $10 \mathrm{~mL}$ of EG $(0.31 \mathrm{~g})$ in $10 \mathrm{~mL}$ of THF were drop-wise added simultaneously for 40 min using two addition funnels in order to maintain the reagents equimolarity in the reaction mixture. The reaction was finished by adding $1 \mathrm{~mL}$ of water followed by 5 $\mathrm{mL}$ of $1 \mathrm{M} \mathrm{HCl}$, and after stirring for $5 \mathrm{~min}$, it was diluted with $\mathrm{DCM}$ and filtered. The filtrate was washed with $0.1 \mathrm{M} \mathrm{HCl}$, dried on $\mathrm{MgSO}_{4}$, and evaporated to dryness to render a mixture of linear and cyclic oligomers. Linear oligomers were removed by chromatography through a short column of silica gel using a cold mixture of DCM/diethyl ether 90/10 (v/v) as eluent. The cyclic oligomeric mixture was fractionated into individual size species by preparative HPLC using a mixture of hexane/dioxane 60/40 (v/v). $c(\mathrm{BF})_{\mathrm{n}}:{ }^{1} \mathrm{H}$ NMR $\left(\delta \mathrm{ppm}, \mathrm{CDCl}_{3}, 300 \mathrm{MHz}\right): 7.23,7.24$, $7.25(3 \mathrm{~s}, 2 \mathrm{H}), 4.40(\mathrm{~m}, 4 \mathrm{H}), 1.92,1.99(2 \mathrm{~m}, 4 \mathrm{H}),{ }^{13} \mathrm{C} \mathrm{NMR}\left(\delta \mathrm{ppm}, \mathrm{CDCl}_{3}, 75.5 \mathrm{MHz}\right)$ : $158.1,157.9,146.7,146.5,118.7,118.6,118.5,65.0,64.8,25.4 . c(E F)_{n}:{ }^{1} H$ NMR $\left(\delta \mathrm{ppm}, \mathrm{CDCl}_{3}, 300 \mathrm{MHz}\right): 7.37,7.23,7.21(3 \mathrm{~s}, 4 \mathrm{H}), 4.68,4.67,4.65(3 \mathrm{~s}, 4 \mathrm{H}) .{ }^{13} \mathrm{C}$ NMR $\left(\delta \mathrm{ppm}, \mathrm{CDCl}_{3}, 75.5 \mathrm{MHz}\right): 157.6,157.5,146.5,119.3,119.1,62.8$.

Synthesis of cyclic oligomers by cyclodepolymerization (CD). $c(B F)_{n}$ and $c(E F)_{n}$ were also prepared by cyclodepolymerization of PBF and PEF polyesters previously synthesized by melt polycondensation as it will be described below. The procedure recently reported by us $^{29}$ for the preparation of cyclic oligo(hexamethylene terephthalate)s was followed. $0.8 \mathrm{~g}$ of PBF or PEF (previously dried overnight in a vacuum oven at $60{ }^{\circ} \mathrm{C}$ ), $20 \mathrm{~mL}$ of dried DCB and $3 \% \mathrm{~mol}$ of DBTO were introduced into a $50 \mathrm{~mL}$ round-bottom flask fitted with a magnetic stirrer and a condenser. The mixture was stirred for 7 days under reflux and then it was cooled at room 
temperature, filtered, and the solvent evaporated under vacuum at $50{ }^{\circ} \mathrm{C}$. In order to remove the linear oligomers the solid residue was chromatographed on a short column of silica gel using a mixture of DCM and diethyl ether 90/10 (v/v) as eluent. $c(\mathrm{BF})_{\mathrm{n}}$ : Yield: $60 \% .{ }^{1} \mathrm{H}$ NMR $\left(\delta, \mathrm{CDCl}_{3}, 300 \mathrm{MHz}\right): 7.23,7.21,7.20(3 \mathrm{~s}, 2 \mathrm{H}), 4.41$ $(\mathrm{m}, 4 \mathrm{H}), 1.98,1.92(2 \mathrm{~m}, 4 \mathrm{H}) .{ }^{13} \mathrm{C}$ NMR $\left(\delta \mathrm{ppm}, \mathrm{CDCl}_{3}, 75.5 \mathrm{MHz}\right): 158.1,158.0$, 146.7, 146.5, 118.8, 118.6, 118.5, 65.0, 64.9, 64.8. $c(E F)_{n}:{ }^{1} \mathrm{H}$ NMR $\left(\delta p p m, \mathrm{CDCl}_{3}\right.$, $300 \mathrm{MHz}): 7.35,7.23,7.21,(3 \mathrm{~s}, 2 \mathrm{H}), 4.68,4.67,4.65(3 \mathrm{~s}, 4 \mathrm{H}) .{ }^{13} \mathrm{C}$ NMR $(\delta \mathrm{ppm}$, $\left.\mathrm{CDCl}_{3}, 75.5 \mathrm{MHz}\right): 157.6,157.5,146.5,119.3,62.8$. The ${ }^{1} \mathrm{H}$ NMR spectra of the $c(\mathrm{BF})_{\mathrm{n}}$ and $c(\mathrm{EF})_{\mathrm{n}}$ mixtures are accessible in the SI file (Figure SI-2).

Synthesis of PBF and PEF by polycondensation in the melt. Dimethyl 2,5furandicarboxylate (FDCA-Me $)_{2}$ was synthetized following the method reported by Gubbels et al. ${ }^{30}$ based on the Fischer esterification of FDCA with $\mathrm{MeOH}$. A round bottom flask was charged with $25.6 \mathrm{mmol}(4 \mathrm{~g})$ of FDCA, $1.38 \mathrm{~mol}(55.3 \mathrm{~g})$ of $\mathrm{MeOH}$, and $1 \mathrm{~mL}$ of $12 \mathrm{M} \mathrm{HCl}$. The mixture left to react for $18 \mathrm{~h}$ under reflux and the reaction was then stopped by adding $0.5 \mathrm{M}$ methanol solution of $\mathrm{KOH}$. The solution was then evaporated to dryness and the residue extracted with $\mathrm{CHCl}_{3}$. The extract was then washed with water $(200 \mathrm{~mL})$, dried on $\mathrm{MgSO}_{4}$ and evaporated to render a solid that was crystallized from $\mathrm{CHCl}_{3}$ upon adding hexane and cooling. Yield: $75 \%$. m.p.: $112{ }^{\circ} \mathrm{C} ;{ }^{1} \mathrm{H}$ NMR $\left(\delta\right.$ ppm, $\left.\mathrm{CDCl}_{3}, 300 \mathrm{MHz}\right): 3.94(\mathrm{~s}, 6 \mathrm{H}), 7.23(\mathrm{~s}, 2 \mathrm{H}) .{ }^{13} \mathrm{C}$ NMR $\left(\delta \mathrm{ppm}, \mathrm{CDCl}_{3}, 300 \mathrm{MHz}\right): 52.4,118.5,146.9,158.4$. These NMR spectra are accessible in the SI file (Figure SI-3).

The synthesis of PBF and PEF polyesters used for cyclodepolymerization was carried out by polycondensation in the melt following the usual two-steps method repeatedly described in literature. ${ }^{31}$ In the first step (transesterification), $10.9 \mathrm{mmol}(2.0 \mathrm{~g})$ of FDCA-Me $\mathrm{H}_{2}$ was made to react with $23 \mathrm{mmol}(2.15 \mathrm{~g})$ of BD or EG $(1.42 \mathrm{~g})$ in the presence of $5 \mu \mathrm{L}$ of $\mathrm{Sn}(\mathrm{Oct})_{2}$ as catalyst and Irganox 1010 and Irgafos $126(0.1 \%$ relative of the total amount of the monomer $)$ as antioxidants at 
180 and $225^{\circ} \mathrm{C}$ for PBF and PEF, respectively, in a three necked flask provided with mechanical stirring and under a nitrogen atmosphere for $4 \mathrm{~h}$. The transesterification process was followed by ${ }^{1} \mathrm{H}$ NMR spectroscopy and when the FDCA-Me $\mathrm{M}_{2}$ conversion exceeded $95 \%$, the second step of polycondensation was initiated by increasing the temperature up to 220 and $250{ }^{\circ} \mathrm{C}$ for PBF and PEF, respectively, and reducing the pressure to $0.5-1$ mbar. The reaction was left to proceed under such conditions for $4 \mathrm{~h}$. Analysis of the obtained polyesters were performed without previous treatment. PBF: Yield: $85 \%$. m.p.: $168.2{ }^{\circ} \mathrm{C} .{ }^{1} \mathrm{H}$ NMR $(\delta$ ppm, $\left.\mathrm{CDCl}_{3} / \mathrm{TFA}, 300 \mathrm{MHz}\right): 7.34(\mathrm{~s}, 2 \mathrm{H}), 4.49(\mathrm{bm}, 4 \mathrm{H}), 1.97(\mathrm{bm}, 4 \mathrm{H}) \cdot{ }^{13} \mathrm{C}$ NMR $(\delta$ ppm, $\left.\mathrm{CDCl}_{3} / \mathrm{TFA}, 75.5 \mathrm{MHz}\right)$ : 161.1, 147.1, 120.5, 67.2, 25.3. PEF: Yield: $80 \%$. m.p.: $210{ }^{\circ} \mathrm{C} .{ }^{1} \mathrm{H}$ NMR $\left(\delta \mathrm{ppm}, \mathrm{CDCl}_{3} / \mathrm{TFA}, 300 \mathrm{MHz}\right): 7.30(\mathrm{~s}, 2 \mathrm{H}), 4.71(\mathrm{~s}, 4 \mathrm{H}) .{ }^{13} \mathrm{C}$ NMR ( $\delta$ ppm, $\left.\mathrm{CDCl}_{3} / \mathrm{TFA}, 75.5 \mathrm{MHz}\right): 159.3,146.4,120.2,63.8 .{ }^{1} \mathrm{H}$ NMR and ${ }^{13} \mathrm{C}$ NMR spectra of PBF and PEF as well as a brief account of their main characteristics are included in the SI file (Figures SI-4 and Table SI-1).

Synthesis of PBF and PEF by ROP of $c(B F)_{n}$ and $c(E F)_{n} .2 .37 \mathrm{mmol}(0.5 \mathrm{~g})$ of $c(\mathrm{BF})_{\mathrm{n}}$ or $2.7 \mathrm{mmol}(0.5 \mathrm{~g})$ of $c(\mathrm{EF})_{\mathrm{n}}$ coming from $\mathrm{HDC}$ along with $0.5 \% \mathrm{~mol}$ of $\mathrm{Sn}(\mathrm{Oct})_{2}$ were dissolved in $5 \mathrm{~mL}$ of $\mathrm{DCM}$ in a vial and dried under vacuum at room temperature for $24 \mathrm{~h}$. Subsequently, the mixture was made to react for $2 \mathrm{~h}$ into a three-necked round-bottom flask provided with mechanical stirring at 220 and 250 ${ }^{\circ} \mathrm{C}$ for PBF and PEF, respectively. Samples at different times were taken off to follow the evolution in the molecular weight. PBF: ${ }^{1} \mathrm{H}$ NMR $\left(\delta \mathrm{ppm}, \mathrm{CDCl}_{3} / \mathrm{TFA}, 300\right.$ $\mathrm{MHz}): 7.30(\mathrm{~s}, 2 \mathrm{H}), 4.46(\mathrm{~m}, 4 \mathrm{H}), 1.93(\mathrm{~m}, 4 \mathrm{H}) .{ }^{13} \mathrm{C}$ NMR $\left(\delta \mathrm{ppm}, \mathrm{CDCl}_{3} / \mathrm{TFA}, 75.5\right.$ $\mathrm{MHz}): 160.3,146.7,120.0,66.6,25.0 . \mathrm{PEF}:{ }^{1} \mathrm{H}$ NMR ( $\left.\delta \mathrm{ppm}, \mathrm{CDCl}_{3} / \mathrm{TFA}, 300 \mathrm{MHz}\right)$ : 7.29 (s, 2H), $4.70(\mathrm{~s}, 4 \mathrm{H}) \cdot{ }^{13} \mathrm{C}$ NMR ( $\left.\delta \mathrm{ppm}, \mathrm{CDCl}_{3} / \mathrm{TFA}, 75.5 \mathrm{MHz}\right): 159.1,146.3$, 120.1, 63.7.

For the synthesis of PBF from individual $c(B F)_{m}$ species the polymerization reactions were carried out in the DSC. $5 \mathrm{mg}$ of $c(\mathrm{BF})_{2}, c(\mathrm{BF})_{3}$ or $c(\mathrm{BF})_{4}$ and $0.5 \%-\mathrm{mol}$ 
of $\mathrm{Sn}(\mathrm{Oct})_{2}$ were dissolved in $1 \mathrm{~mL}$ of $\mathrm{DCM}$ in a vial and dried under vacuum at room temperature for $24 \mathrm{~h}$. Aliquot amounts of the mixture were then placed in aluminium pans heated at $220{ }^{\circ} \mathrm{C}$ for periods of time going from 5 min up to $2 \mathrm{~h}$. At scheduled times the capsules were opened and the sample analysed by ${ }^{1} \mathrm{H}$ NMR and GPC. ${ }^{1} \mathrm{H}$ NMR (sample obtained from $\left.c(\mathrm{BF})_{2}\right)\left(\delta \mathrm{ppm}, \mathrm{CDCl}_{3} / \mathrm{TFA}, 300 \mathrm{MHz}\right): 7.32(\mathrm{~s}, 2 \mathrm{H})$, $4.48(\mathrm{~m}, 4 \mathrm{H}), 1.95(\mathrm{~m}, 4 \mathrm{H}) .{ }^{13} \mathrm{C}$ NMR $\left(\delta \mathrm{ppm}, \mathrm{CDCl}_{3} / \mathrm{TFA}, 75.5 \mathrm{MHz}\right): 161.1,147.1$, $120.5,67.2,25.3$

\section{RESULTS AND DISCUSSION}

\section{Synthesis and characterization of cyclic oligo(alkylene 2,5-furandicarboxylate)s.}

The synthesis of the cyclic oligo(alkylene 2,5-furandicarboxylate)s, abbreviated $c(A F)_{n}$ with $\mathrm{A}$ being ethylene or butylene, was carried out by two well-known cyclization methods, namely pseudo-high dilution (HDC) and cyclodepolymerization (CDP). Results obtained by both methods are compared in Table 1.

The HDC method was developed by Brunelle et al. ${ }^{32}$ for the synthesis of a variety of macrocycles containing carbonate or carboxylate functions. The method consists of mixing carefully highly diluted solutions of the diacyl dichloride and the appropriate diol in the presence of catalytic amounts of DABCO and one equivalent of trimethylamine. The application of this method to the preparation of $c(\mathrm{AF})_{\mathrm{n}}$ required previously the preparation of the 2,5-furandicarbonyl dichloride $\left(\mathrm{FDCA}-\mathrm{Cl}_{2}\right)$, which was successfully achieved by reaction of commercial 2,5-furandicarboxylic acid with $\mathrm{SOCl}_{2}$. The cyclization reaction was conducted in $\mathrm{DCM}$ at $0{ }^{\circ} \mathrm{C}$ and using reagents concentrations of around $5 \mathrm{mM}$. The crude reaction product was obtained in $\sim 80 \%$ yield, and by ${ }^{1} \mathrm{H}$ NMR, it was shown to contain mostly cyclic oligomers accompanied by a small amount of linear species (Figure SI-5). The linear species could be efficiently removed by flash chromatography and the purified product, which was obtained in around $65 \%$ yield, consisted of a mixture of cyclic oligomers of varying small size whose ${ }^{1} \mathrm{H}$ NMR spectra did not present detectable signals arising from hydroxyl or 
carboxylic end groups (Figure 1). As it is shown in Figure 2, the analysis of the purified $(\mathrm{AF})_{\mathrm{m}}$ mixtures by HPLC chromatography combined with MALDI-ToF spectrometry revealed that they mainly contained dimer, trimer and tetramer cycles together with minor amounts of pentamer and others cycles of larger sizes. Cyclic dimer and trimer together accounted for about $90 \%$ of the content of both $c(B F)_{n}$ and $c(E F)_{n}$ mixtures but the ratio of these two species in the two mixtures was almost reversed. The $c(B F)_{n}$ mixture was fractionated by semipreparative HPLC with a yield higher than $80 \%$ to render homogeneous fractions of $c(\mathrm{BF})_{2}, c(\mathrm{BF})_{3}$ and $c(\mathrm{BF})_{4}$ species whose cycle size and purity could be ascertained by MALDI-Tof analysis (Figure 3). The ${ }^{1} \mathrm{H}$ NMR spectra of these fractions showed specific signals according to cycle size so that a clear distinction between dimer and higher size cycles is feasible by comparing to each other. These spectra are shown in Figure SI-6 of the SI file. The heating DSC traces of these fractions together with those registered for the $c(\mathrm{BF})_{\mathrm{n}}$ and $c(\mathrm{EF})_{\mathrm{n}}$ mixtures are compared in Figure 4a. Prominent endothermal peaks arising from melting and appearing at temperatures increasing with cycle size were recorded from the three homogeneous $c(\mathrm{BF})_{\mathrm{n}}$ fractions. On the other hand, the DSC trace registered from the $c(B F)_{n}$ mixture displayed a broad peak centered at $\sim 147^{\circ} \mathrm{C}$ and covering the range of temperatures observed for the three isolated fraction peaks. The DSC trace of the $c(\mathrm{EF})_{\mathrm{n}}$ mixture displayed a peak of similar features to that of $c(\mathrm{BF})_{\mathrm{n}}$ but displaced about $40{ }^{\circ} \mathrm{C}$ higher, which is a result according to the $T_{\mathrm{m}}$ values of their respective derived polymers PBF $\left(\sim 170^{\circ} \mathrm{C}\right)$ and $\operatorname{PEF}\left(\sim 210^{\circ} \mathrm{C}\right)$. The crystallinity present in both individual and mixed samples was corroborated by powder X-ray diffraction at wide angles which provided patterns containing peaks characteristic of crystalline material that disappeared upon heating at temperatures above melting. (Figure SI-7). The thermal stability of the $c(\mathrm{BF})_{\mathrm{n}}$ and $c(\mathrm{EF})_{\mathrm{n}}$ mixtures was examined by TGA under inert atmosphere and the traces registered from the two mixtures are compared in Figure 4b. The two samples started to lose weight at temperatures near to $300{ }^{\circ} \mathrm{C}$ with the weight fall happening at $\sim 380^{\circ} \mathrm{C}$ and $\sim 390^{\circ} \mathrm{C}$ for $c(\mathrm{EF})_{\mathrm{n}}$ and $c(\mathrm{BF})_{\mathrm{n}}$, respectively. 
The preparation of $c(\mathrm{AF})_{\mathrm{n}}$ by $\mathrm{CDP}$ was then explored given the relevance that this method has to the potential chemical recycling of PAF polyesters. We have recently made use of this method with success for the synthesis of cyclic oligo(hexamethylene terephthalate)s. ${ }^{29}$ In this case the previously synthesized PBF and PEF polyesters were dissolved in DCB and subjected to heating at $180^{\circ} \mathrm{C}$ in the presence of DBTO. Results were no very far from those obtained by the HDC method so that cyclic oligomeric mixtures comprising essentially dimer, trimer and tetramer were obtained in approximate $60 \%$ yields for both $c(E F)_{n}$ and $c(B F)_{n}$ (Figure 5). However significant differences in cycle size composition were observed between the two methods with a more equilibrated proportion being obtained by the HDC method. Such differences are particularly noticeable for $c(B F)_{n}$ where the $c(B F)_{2} / c(B F)_{3}$ ratio changed approximately from 2 to 1 according to cyclization was induced either by condensation or depolymerization (Table 1). Since CDP took place at high temperatures and long times, it is probably that transesterification reactions involving interconversion of cycles of different sizes happened along with cycle formation. On the contrary, the low temperatures and short times applied for HDC are unfavorable conditions for the occurrence of interconversion reactions so cycle sizes initially generated in the condensation reaction would be preserved. The different compositions observed for the $(\mathrm{AF})_{\mathrm{m}}$ mixtures could therefore respond to which kind of driven factor, thermodynamic or kinetics, is operating in the process.

Synthesis of poly(alkylene 2,5-furandicarboxylate)s by ROP. The synthesis of poly(butylene 2,5-furandicarboxylate) (PBF) and poly(ethylene 2,5-furandicarboxylate) (PEF) was accomplished by ROP of $c(B F)_{n}$ and $c(E F)_{n}$ mixtures respectively, by applying the usual melt procedure catalyzed by $\mathrm{Sn}(\mathrm{Oct})_{2}$. As it is shown in Figure 6, the chemical constitution and purity of the resulting polyesters was ascertained by ${ }^{1} \mathrm{H}$ NMR. It is worthy to note that no signals arising from diethylene glycol units were detected in the PEF spectrum despite that etherification involving hydroxyl end groups is a 
secondary reaction difficult to avoid in melt polycondensation (compare with the ${ }^{1} \mathrm{H}$ NMR spectra recorded from PEF obtained by polycondensation which is shown in Figure SI-4). In order to investigate the influence of cycle size on the ROP of $c(\mathrm{AF})_{\mathrm{n}}$, the homogeneous fractions $c(\mathrm{BF})_{2}, c(\mathrm{BF})_{3}$ and $c(\mathrm{BF})_{4}$ were polymerized under identical conditions to those used for the $c(\mathrm{BF})_{\mathrm{n}}$ mixture, and polymer growing was compared for the four systems. The study was also extended to the polymerization of the $c(E F)_{n}$ mixture in order to compare results for different alkylene units. Polymer growing was estimated by following the evolution of the molecular weight of the forming polyester with time by GPC analysis of the reaction mass. The changes observed in both weightand number-average molecular weights along reaction time for polymerizations carried out at different temperatures are shown in Figure 7. The inspection of these plots leads to conclude the following: a) $c(\mathrm{BF})_{\mathrm{n}}$ polymerized initially faster than $c(\mathrm{EF})_{\mathrm{n}}$ but after two hours of reaction similar molecular weights were reached in the two systems. In fact, an asymptotic profile was observed in the first case whereas a tendentiously linear trend was displayed by the second one. b) The molecular weight increasing rate was found to be higher for smaller cycle sizes although such differences are mild and tend to disappear at high conversions. c) The profiles obtained for the $c(B F)_{n}$ mixture were comparable to those of the individual fractions revealing that polymerization proceeded in this case at an approximate average rate. d) As expected, the polymerization rate increased with temperature with variations being larger for $c(B F)_{n}$ than for $c(E F)_{n}$; furthermore polymerization of $c(\mathrm{EF})_{\mathrm{n}}$ required higher temperatures than $c(\mathrm{BF})_{\mathrm{n}}$ to attain similar molecular weights.

The thermal properties of the PBF and PEF polyfuranoates samples obtained after reaction for two hours at $240^{\circ} \mathrm{C}$ were then evaluated. The DSC and TGA traces registered from them are depicted in Figure 8 and their most characteristic parameters are collected in Table 2. Ranges of data reported by different authors for these polyesters prepared by melt polycondensation are also included for comparison. As it can be seen, the polyfuranoates obtained by ROP display molecular weights perfectly 
comparable to those obtained by polycondensation or even higher. The same can be said about the decomposition, glass transition and melting temperatures.

A brief comment on the paper recently published on $\mathrm{PBF}^{28}$ obtained by ROP should be made. In such work, PBF was synthesized from a mixture of cyclic (butylene 2,5-furandicarboxylate)s enriched in trimers and tetramers and with an average cycle size significantly larger than that of the mixtures used in the present work. The polymerization was there conducted in a DSC pan with the oligomeric sample mixed with tetrakis(2-ethylhexyl) titanate catalyst and heating at $270{ }^{\circ} \mathrm{C}$ for $15 \mathrm{~min}$. The PBF thus obtained showed a number-average molecular weight about $6,000 \mathrm{~g} \cdot \mathrm{mol}^{-1}$ and values of $T_{g}$ and $T_{m}$ of $35^{\circ} \mathrm{C}$ and $169{ }^{\circ} \mathrm{C}$, respectively. In the light of our results (Figure 8) may be inferred that the relative low molecular weight obtained for PBF in that work is very likely due to the short polymerization time applied and also to the relative larger cycle sizes used for feeding. The low transition temperatures that are observed for the synthesized sample is nothing more than a consequence of its low molecular weight; the strong dependence of thermal parameters on molecular weight in PAF's is a wellknown fact.

\section{Conclusion}

In the present work, PBF and PEF were successfully synthesized by ring opening polymerization catalyzed by $\mathrm{Sn}(\mathrm{Oct})_{2}$. The cyclic oligoesters used for feeding could be prepared in high yields by both high-dilution and thermal cyclodepolymerization methods as mixtures containing substantially from dimer to tetramer species. The cyclic oligo(butylene 2,5-furandicarboxylate) mixture could be fractionated by semi-preparative HPLC to provide homogeneous dimer, trimer and tetramer fractions. Polymerization of mixtures and individual fractions under the same conditions revealed that polymerization rate was favored by smaller cycle sizes. It was also found that the oligo(ethylene 2,5-furandicarboxylate) cycles were more reluctant to polymerize than the butylene ones and they required higher 
reaction temperature to reach similar conversions. In all cases, polyfuranoates of high molecular weight, exempted of detectable chain defects, and displaying thermal parameters in perfect agreement with those reported in the literature for the same polymers prepared by polycondensation were obtained in good yields. The results reported in this paper demonstrate the potential of the ring opening polymerization method as a suitable option for the synthesis of poly(alkylene furanoate)s.

\section{Acknowledgements}

Financial support for this research was given by MINECO with grant MAT2012-38044-CO3-03. J. Carlos Morales thanks to CONACYT (Mexico) for the Ph.D. grant awarded. Authors are indebted to Ana Gamarra Montes for her assistance with XRD experiment and data processing.

\section{References}

1. T. Werpy, G. Petersen, Top Value Added Chemicals from Biomass. Volume IResults of Screening for Potential Candidates from Sugars and Synthesis Gas, Pacific Northwest National Laboratory, U.S. Department of Energy: Washington, DC, 2004.

2. A. Corma, S. Iborra, A. Velty, Chem. Rev. 107 (6) (2007) 2411-2502.

3. C. Vilela, A. Sousa, A. Fonseca, A. Serra, J. Coelho, C. Freire, A. Silvestre, Polym. Chem. 5 (2014) 3119-3141.

4. A. Gandini, Polym. Chem. 1 (2010) 245-251.

5. A. Gandini, T.M. Lacerda, Prog. Polym. Sci. 48 (2015) 1-39.

6. A.F. Sousa, C. Vilela, A.C. Fonseca, M. Matos, C.S. Freire, G.J.M. Gruter, J.F.J. Coelho, A.J.D. Silvestre, Polym. Chem. 6 (33) (2015) 5961-5983.

7. M. Gomes, A. Gandini, J.D. Silvestre, B. Reis, J. Polym. Sci. Part A Polym. Chem. 49 (17) (2011) 3759-3768. 
8. J. Ma, X. Yu, J. Xu, Y. Pang, Polymer 53 (19) (2012) 4145-4151.

9. J. Zhu, J. Cai, W. Xie, P. Chen, M. Gazzano, M. Scandola, R. Gross, Macromolecules 46 (3) (2013) 796-804

10. J. Ma, Y. Pang, M. Wang, J. Xu, H. Ma, X. Nie, J. Mater. Chem. 22 (2012) 34573461.

11. a) L. Wu, R. Mincheva, Y. Xu, J.M. Raquez, P. Dubois, Biomacromolecules 13 (9) (2012) 2973-2981. b) B. Wu, Y. Xu, Z. Bu, L. Wu, B-G. Li, P. Dubois, Polymer 55 (16) (2014) 3648-3655.

12. M. Matos, A. Sousa, A. Fonseca, C. Freire, J. Coelho. A. Silvestre, Macromol. Chem. Phys. 215 (22) (2014) 2175-2184.

13. N. Jacquel, R. Saint-Loup, J.P. Pascault, A. Rousseau, F. Fenouillot, Polymer 59 (2015) 234-242.

14. J. Wu, S. Thiyagarajan, B.A.J. Noordover, D.S. Van Es, C.E. Koning, Chemsuschem 8 (1) (2015) 67-72.

15. R.J.I. Knoop, W. Vogelzang, J. Van Haveren, D.S. Van Es, J. Polym. Sci. Part A Polym. Chem. 51 (19) (2013) 4191-4199.

16. S.K. Burgess, J.E. Leisen, B.E. Kraftschik, C.R. Mubarak, R.M. Kriegel, W.J. Koros, Macromolecules 47 (4) (2014) 1383-1391.

17. a) G.Z. Papageorgiou, V. Tsanaktsis, D.G. Papageorgiou, S. Exarhopoulos, M. Papageorgiou, D.N. Bikiaris, Polymer 55 (16) (2014) 3846-3858. b) G.Z. Papageorgiou, D.G. Papageorgiou, V. Tsanaktsis, D.N. Bikiaris, Polymer 62 (2015) 28-38.

18. M. Okada, K. Tachikawa, K. Aoi, J. Polym. Sci. Part A Polym. Chem. 35 (13) (1997) 2729-2737.

19. W. Zhou, X. Wang, B. Yang, Y. Xu, W. Zhang, Y. Zhang, J. Ji, Polym. Degrad. Stab. 98 (11) (2013) 2177-2183.

20. G.M. Gruter, L. Sipos, M. A. Dam, Comb. Chem. High Throughput Screening 15 (2) (2012) 180-188.

21. P. Hodge, Chem. Rev. 114 (4) (2014) 2278-2312.

22. D.J. Brunelle, J.E. Bradt, J. Serth-Guzzo, T. Takekoshi, T. Evans, E.J. Pearce, P. Wilson, Macromolecules 31 (15) (1998) 4782-4790.

23. J.H. Youk, A. Boulares, R.P Kambour, W.J. MacKnight, Macromolecules 33 (10) (2000) 3600-3605. 
24. L. Conzzatti, M. Alessi, P. Stagnaro, P. Hodge, J. Polym. Sci. Part A Polym. Chem. 49 (4) (2011) 995-1005.

25. A.R. Tripathy, W.J. MacKnight, S.N. Kukureka, Macromolecules 37 (18) (2004) 6793-6800.

26. W. Bahloul, V. Bounor-Legaré, F. Fenouillot, P. Cassagnau, Polymer 50 (12) (2009) 2527-2534.

27. P. Hodge, Polym. Adv. Tech. 26 (7) (2015) 797-803.

28. D. Pfister, G. Storti, F. Tancini, L.I. Costa, M. Morbidelli, Macromol. Chem. Phys. 216 (21) (2015) 2141-2146.

29. a) N. González-Vidal, A. Martínez de llarduya, V. Herrera, S. Muñoz-Guerra, Macromolecules 41 (12) (2008) 4136-4146. b) G. Giammanco, A. Martínez de Ilarduya, A. Alla, S. Muñoz-Guerra, Biomacromolecules 11 (9) (2010) 2512-2520.

30. E. Gubbels, L. Jasinska-Walc, C.E. Koning, J. Polym. Sci. Part A Polym. Chem. 51 (4) (2013) 890-898.

31. J. Sheirs, T.E. Long, “Modern Polyesters” Wiley 2003.

32. D.J. Brunelle, J. Polym. Sci. Part A Polym. Chem. 46 (4) (2008) 1151-1164. 
Table 1. Cyclic (Alkylene 2,5-furandicarboxylate) Oligomers: Compared Synthesis Results.

\begin{tabular}{|c|c|c|c|c|c|c|}
\hline Method $^{\mathrm{a}}$ & $c(\mathrm{AF})_{\mathrm{n}}$ & Precursors & \multicolumn{2}{|c|}{ Yield $(\%)^{b}$} & \multicolumn{2}{|c|}{ Composition $(n: 2 / 3 / 4)^{c}$} \\
\hline & & & Crude & Flashed & Mixture & Fractionated \\
\hline HDC & $\begin{array}{l}c(\mathrm{BF})_{\mathrm{n}} \\
c(\mathrm{EF})_{\mathrm{n}}\end{array}$ & $\begin{array}{l}\mathrm{FDCA}-\mathrm{Cl}_{2}+\mathrm{BD} \\
\mathrm{FDCA}-\mathrm{Cl}_{2}+\mathrm{EG}\end{array}$ & $\begin{array}{l}80 \\
78\end{array}$ & $\begin{array}{l}67 \\
64\end{array}$ & $\begin{array}{l}62 / 30 / 8 \\
20 / 74 / 6\end{array}$ & $\begin{array}{l}\text { 50/22/9 } \\
\text { n.d. }\end{array}$ \\
\hline CD & $\begin{array}{l}c(B F)_{n} \\
c(E F)_{n}\end{array}$ & $\begin{array}{l}\text { PBF } \\
\text { PEF }\end{array}$ & $\begin{array}{l}74 \\
72 \\
\end{array}$ & $\begin{array}{l}60 \\
60 \\
\end{array}$ & $\begin{array}{l}41 / 49 / 10 \\
24 / 58 / 18\end{array}$ & $\begin{array}{c}33 / 35 / 9 \\
\text { n.d. }\end{array}$ \\
\hline
\end{tabular}

${ }^{\mathrm{a}} \mathrm{HDC}$ : High Dilution Cyclization carried out in $\mathrm{DCM}$ at $0^{\circ} \mathrm{C}$ in the presence of DABCO/TEA; CD: Cyclodepolymerization reaction carried out in DCB at $180^{\circ} \mathrm{C}$ catalysed by DBTO.

${ }^{b}$ Yields for the crude oligomeric mixture and after removal of the linear species (flashed).

${ }^{\circ}$ Composition in $c(\mathrm{BF})_{2}, c(\mathrm{BF})_{3}$ and $c(\mathrm{BF})_{4}$ before and after fractionation. n.d: not determined.

Table 2. Compared Properties of Poly(alkylene 2,5-furandicarboxylate)s Obtained by ROP and Melt Polycondensation.

\begin{tabular}{|c|c|c|c|c|c|c|c|}
\hline Method & PAF & Monomer & $\begin{array}{c}M_{\mathrm{w}}{ }^{\mathrm{a}} \\
\left(\mathrm{g} \cdot \mathrm{mol}^{-1}\right)\end{array}$ & $\oplus^{a}$ & $\begin{array}{l}T_{o}{ }^{b} \\
\left({ }^{\circ} \mathrm{C}\right)\end{array}$ & $\begin{array}{l}T_{g}{ }^{\mathrm{C}} \\
\left({ }^{\circ} \mathrm{C}\right)\end{array}$ & $\begin{array}{l}T_{\mathrm{m}}{ }^{\mathrm{c}} \\
\left({ }^{\circ} \mathrm{C}\right)\end{array}$ \\
\hline \multicolumn{8}{|l|}{ ROP } \\
\hline \multicolumn{8}{|c|}{ PBF } \\
\hline & & $c(\mathrm{BF})_{\mathrm{n}}$ & 58,000 & 2.3 & 273 & 41 & 168 \\
\hline & & $c(\mathrm{BF})_{2}$ & 65,000 & 1.9 & nd & 40 & 171 \\
\hline & & $c(\mathrm{BF})_{3}$ & 59,900 & 2.0 & nd & 42 & 169 \\
\hline & & $c(\mathrm{BF})_{4}$ & 57,000 & 2.1 & nd & 41 & 168 \\
\hline \multicolumn{8}{|c|}{ PEF } \\
\hline & & $c(\mathrm{EF})_{\mathrm{n}}$ & 55,000 & 1.4 & 337 & 80 & 215 \\
\hline
\end{tabular}

$P C^{d}$

PBF

FDCA $\quad 65,000-\quad 2.8-\quad 310-400 \quad 30-\quad 168-$

PEF

FDCA $\quad 47,000-\quad 2.4-\quad 300-390 \quad 80-\quad 200-$

$\begin{array}{lllll}\text { FDCA- } & 80,000^{\mathrm{e}} & \text { n.d } & \text { n.d } & 239\end{array}$

${ }^{a}$ Weight-average molecular weight and dispersity measured by GPC.

${ }^{b}$ Onset degradation temperature corresponding to $10 \%$ of mass loss measured by TGA.

${ }^{\circ}$ Glass transition and melting temperatures measured by DSC.

${ }^{\mathrm{d}}$ PBF and PEF obtained by polycondensation in the melt from FDCA or FDCA-Me ${ }_{2}$ and BD or EG; data

expressed as ranges of values reported in references 7-15.

${ }^{\text {e}}$ After SSP (solid-state postpolycondensation). 
<smiles>CC(=O)c1ccc(C(=O)OCCOC(C)(C)C)cc1</smiles><smiles>CC(C)(C)OCCCCOC(=O)c1ccc(C(C)(C)C)cc1</smiles><smiles>CC(C)(C)OCCOC(=O)c1ccc(C(=O)C(C)(C)C)o1</smiles><smiles>CC(C)(C)OCCCCOC(=O)c1ccc(C(=O)OCCCCBr)o1</smiles>

Scheme 1. Aliphatic-aromatic polyesters from terephthalic acid and 2,5-furandicarboxylic acid.

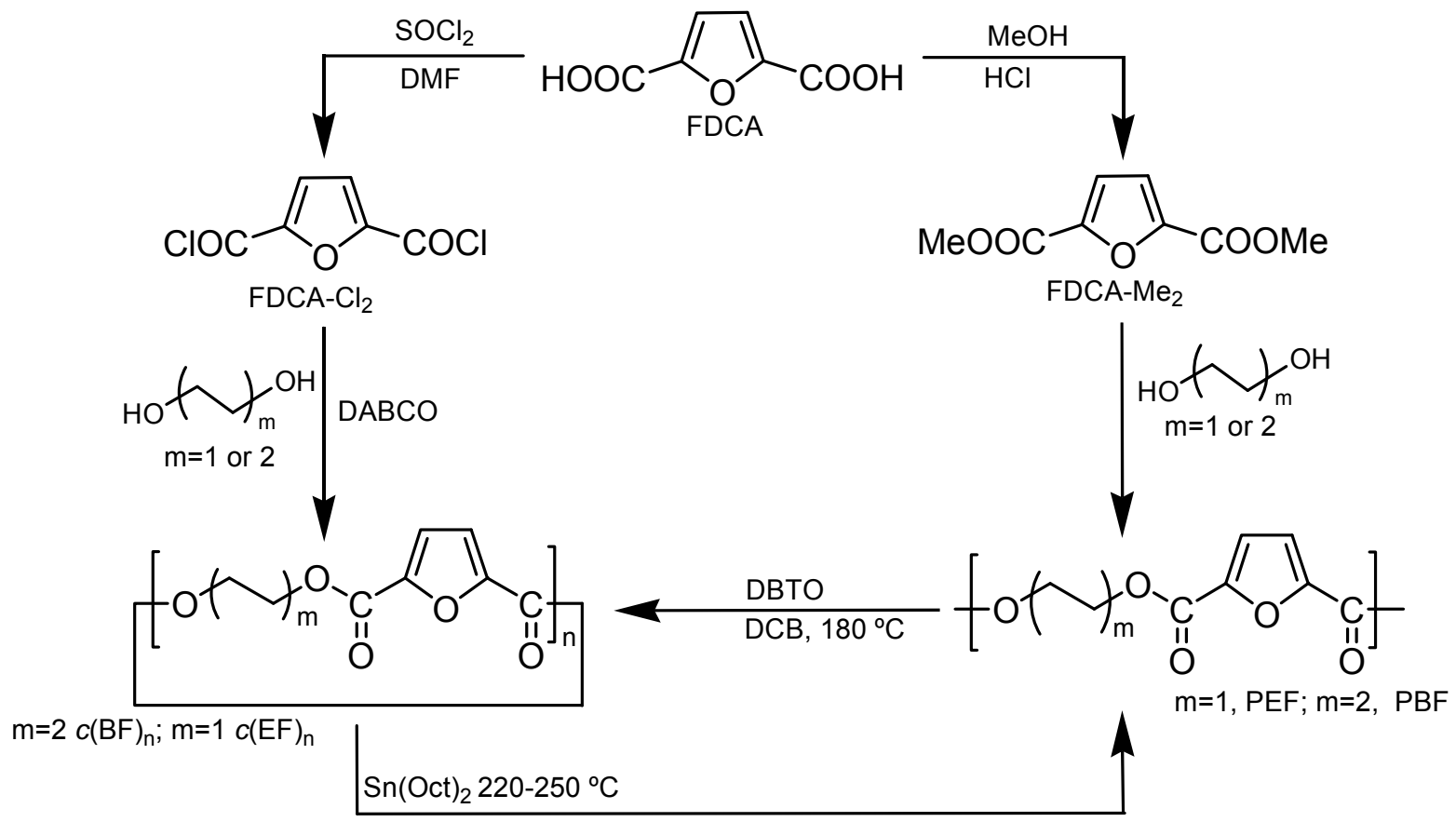

Scheme 2. Synthesis of PEF and PBF by ROP of cyclic oligo(alkylene 2,5-furandicarboxylate)s prepared either by condensation in solution or by cyclodepolymerization. 

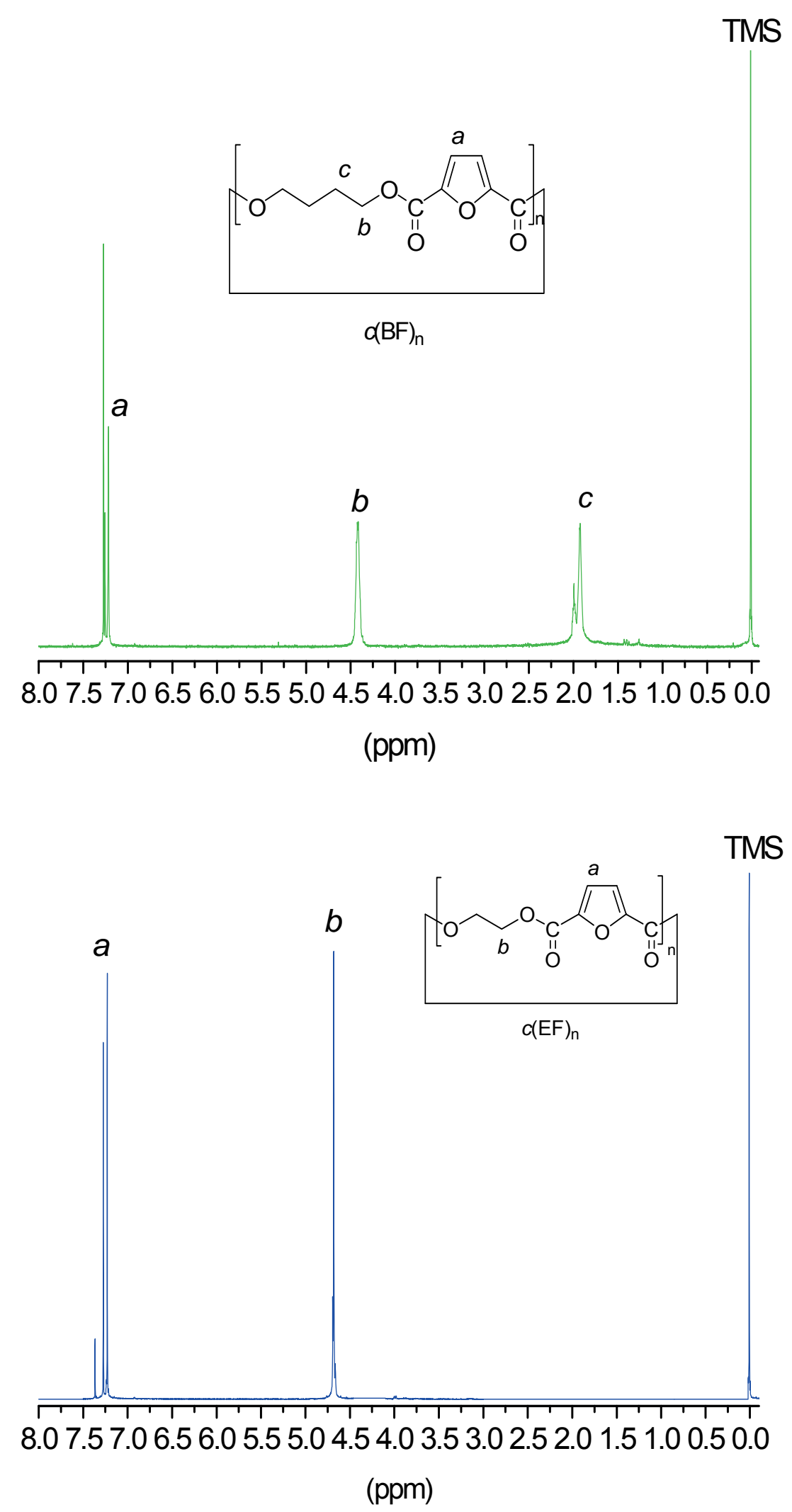

Figure 1. ${ }^{1} \mathrm{H}$ NMR spectra of cyclic oligomers $c(\mathrm{BF})_{\mathrm{n}}$ (top) and $c(\mathrm{EF})_{\mathrm{n}}$ (bottom) mixtures prepared by HDC with indication of peak assignments. 

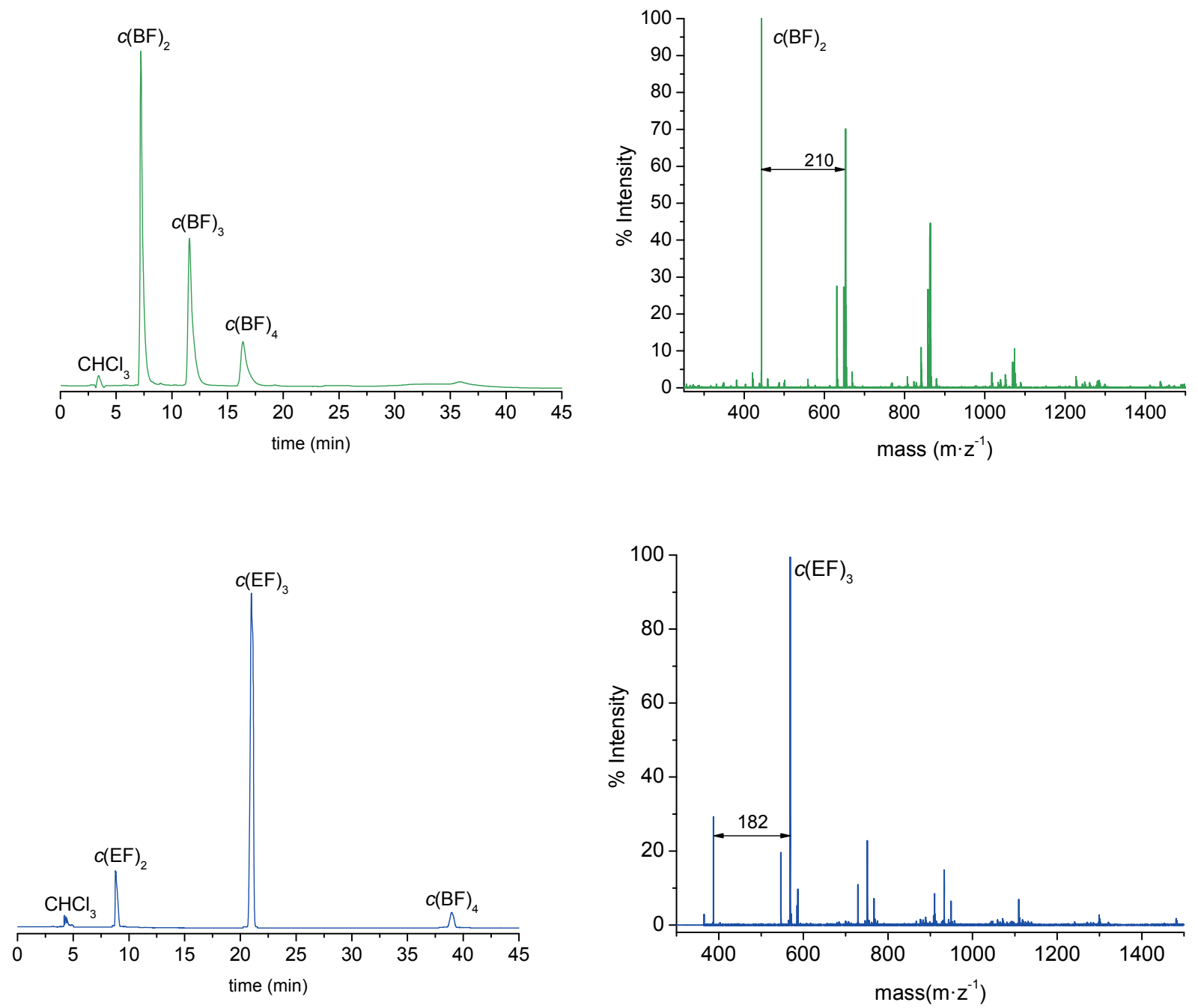

Figure 2. HPLC chromatograms (left) and MALDI-TOF (right) spectra of cyclic oligomers $c(B F)_{n}$ (top) and $c(E F)_{n}$ (bottom) mixtures obtained by HDC. 

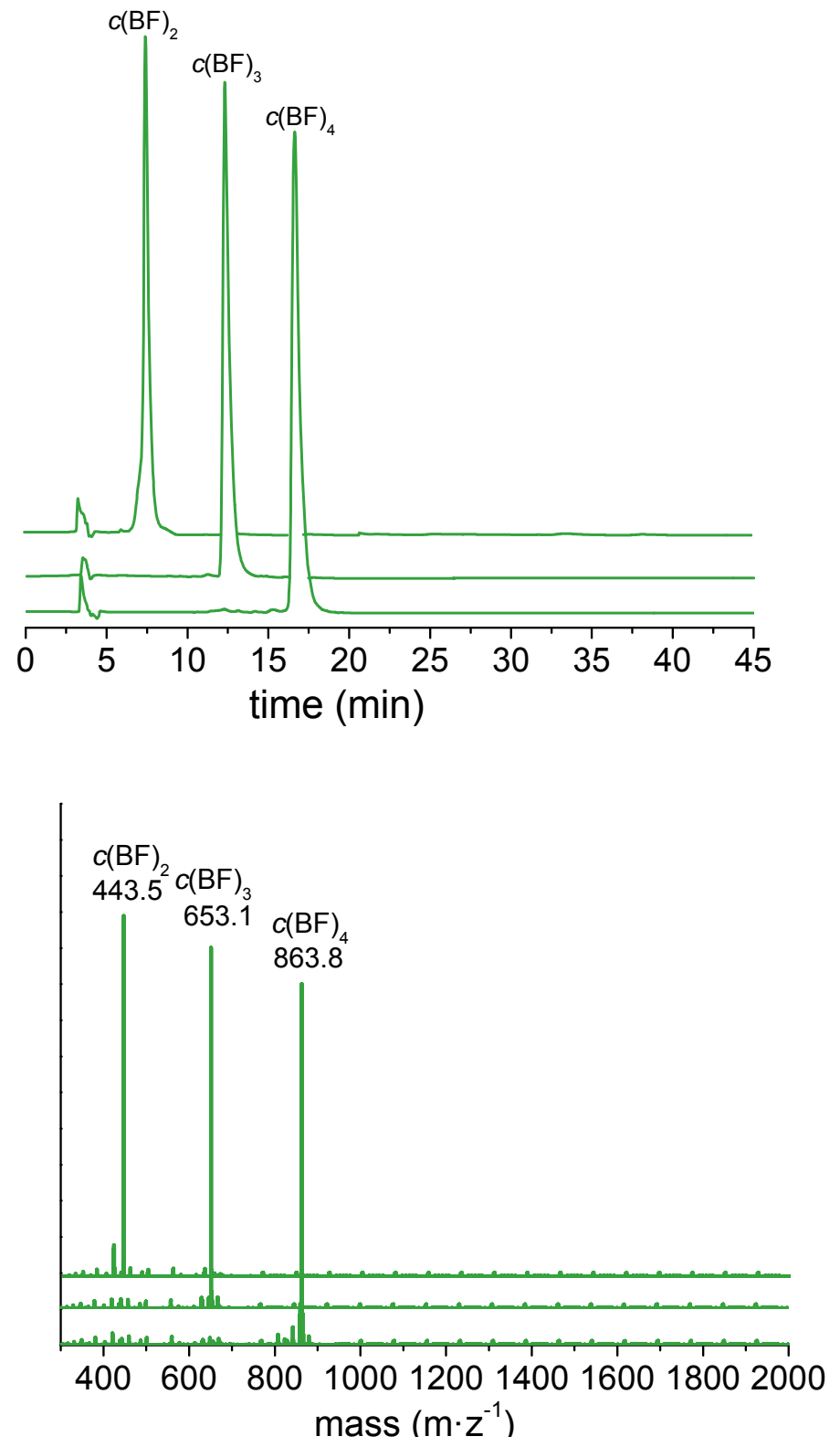

Figure 3. HPLC chromatograms (top) and MALDI-TOF spectra (bottom) of individual cyclic oligo(butylene 2,5-furandicarboxylate)s obtained by HDC. 

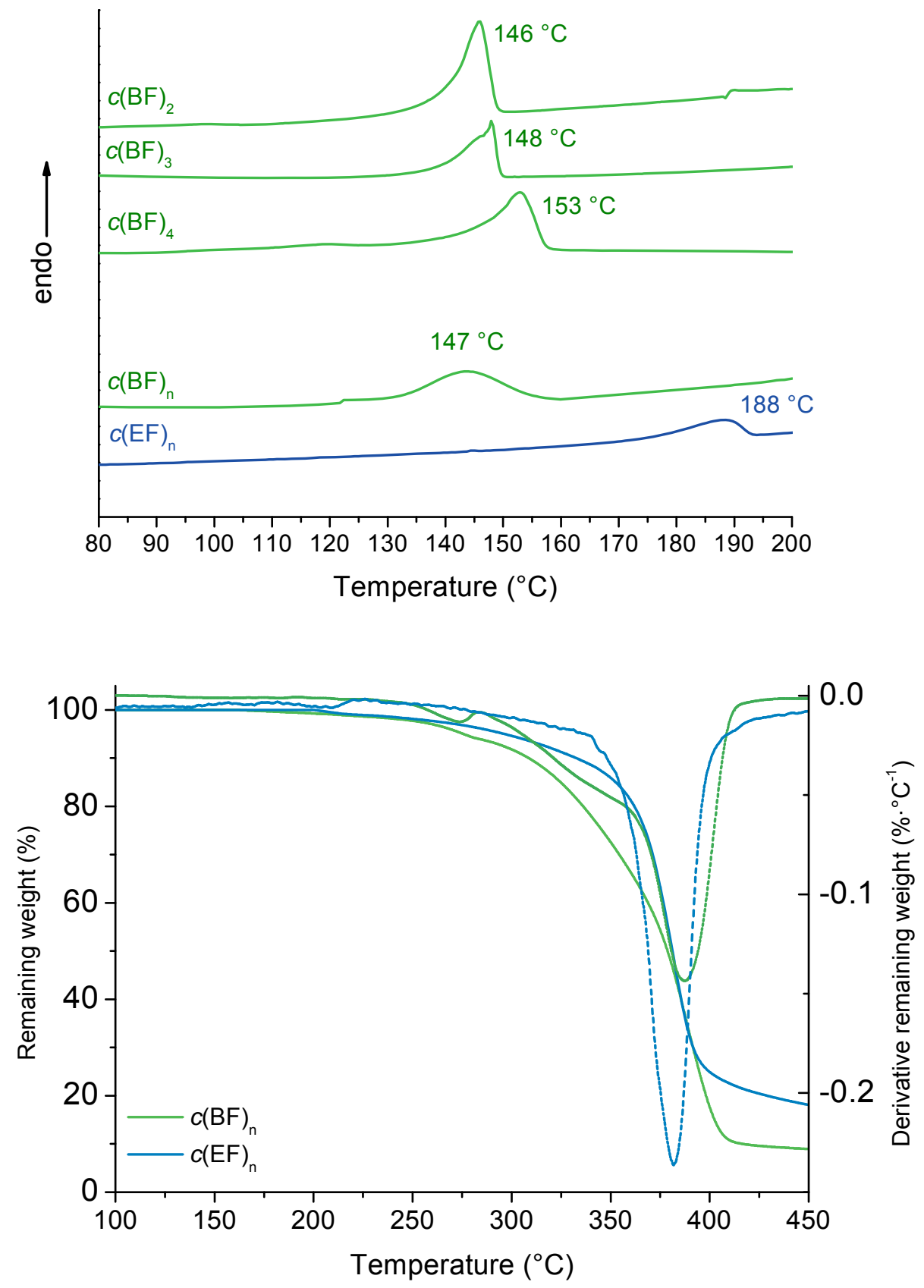

Figure 4. Top: DSC of individual cyclic oligo(butylene 2,5-furandicarboxylate)s and $c(\mathrm{BF})_{\mathrm{n}}$ and $c(\mathrm{EF})_{\mathrm{n}}$ mixtures. Bottom: TGA traces of $c(\mathrm{BF})_{\mathrm{n}}$ and $c(\mathrm{EF})_{\mathrm{n}}$ mixtures and their derivative curves. 

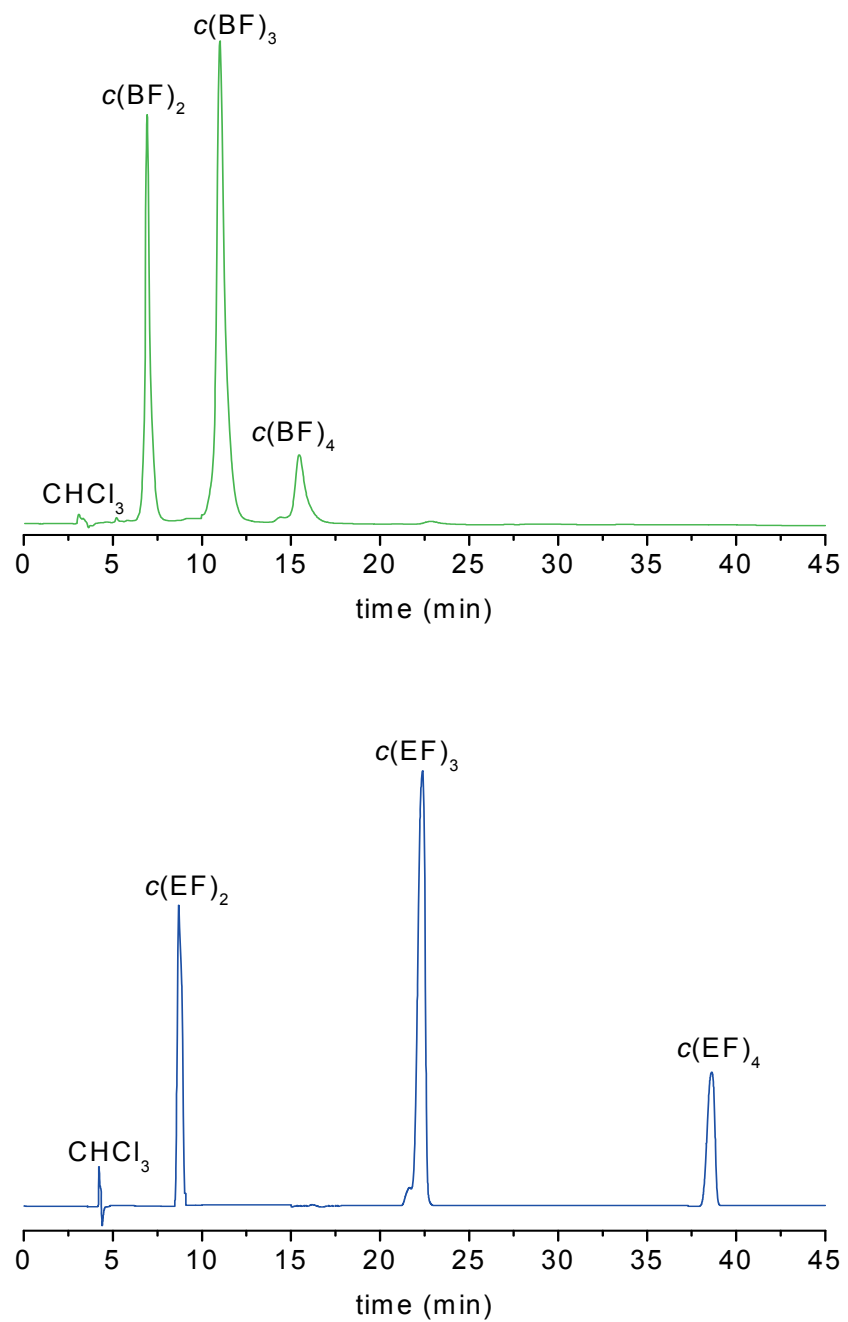

Figure 5. HPLC of $c(B F)_{n}$ (top) and $c(E F)_{n}$ (bottom) prepared by $C D$. 


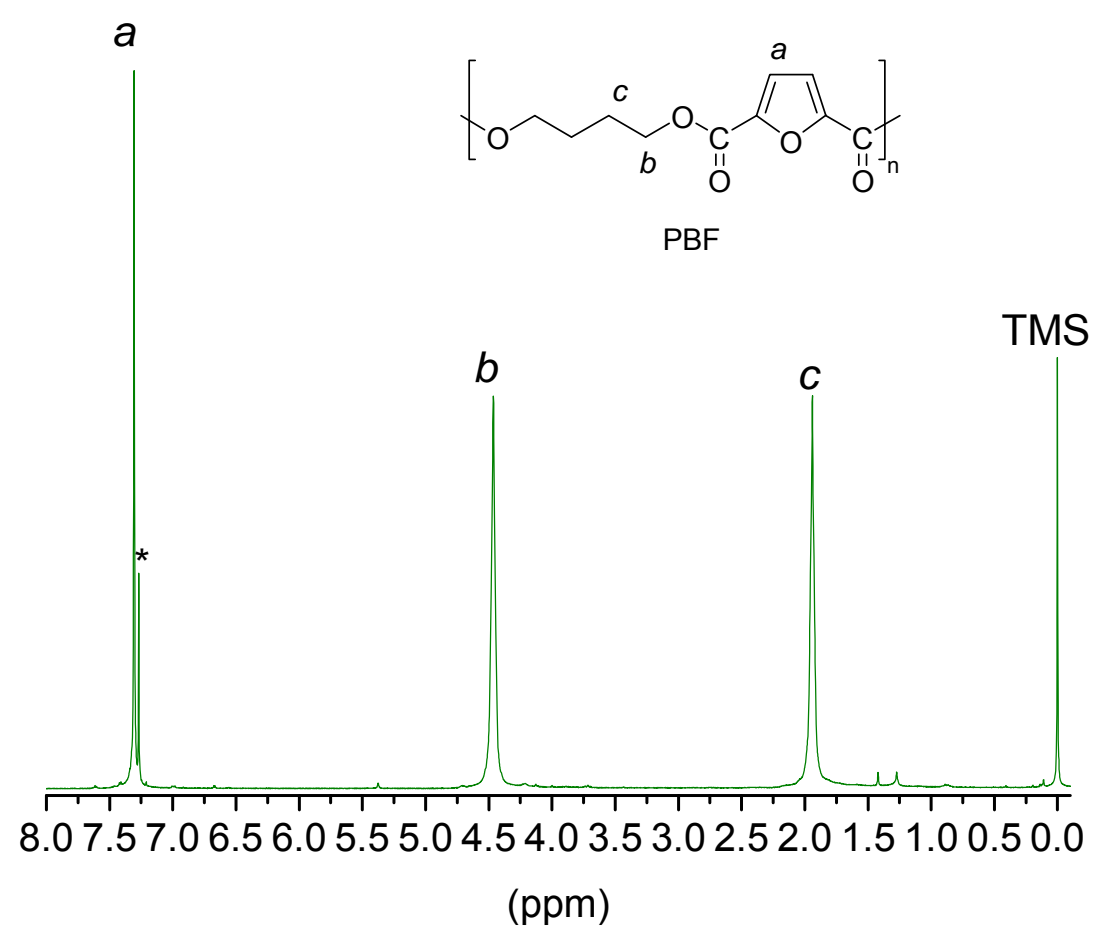

TMS
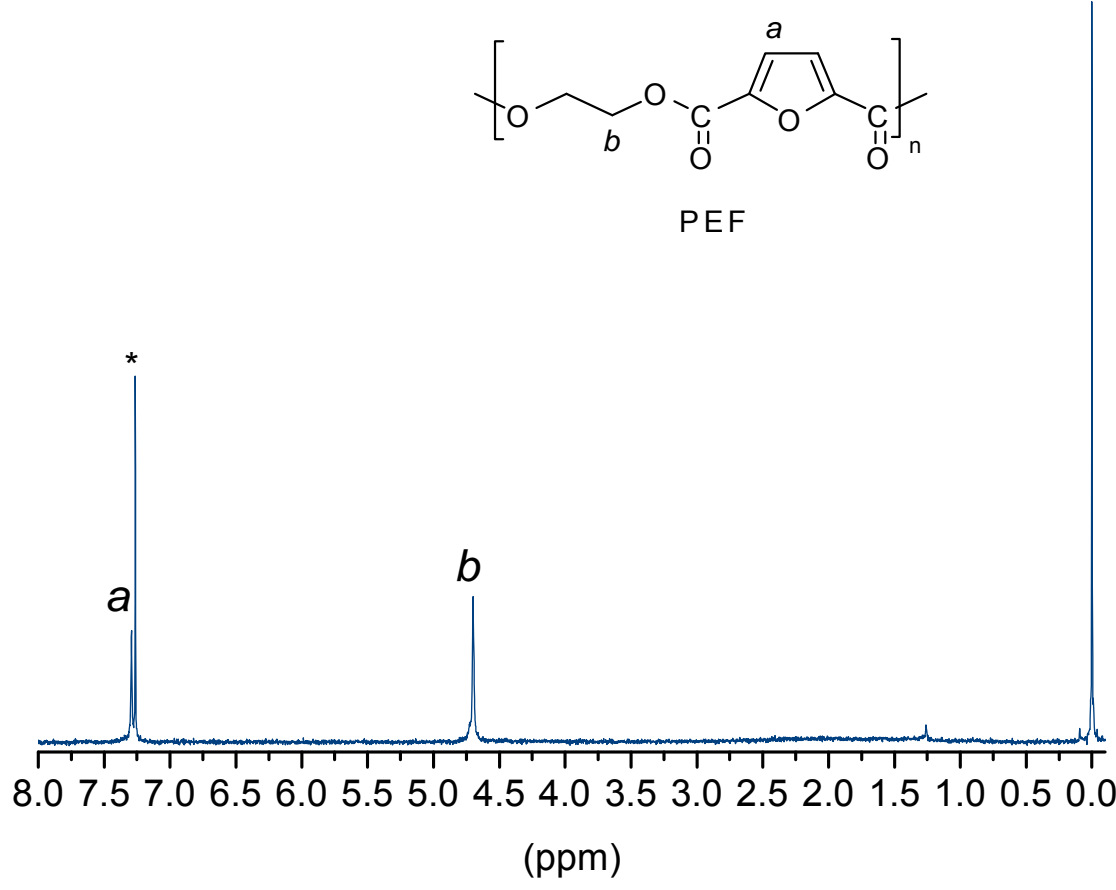

Figure 6. ${ }^{1} \mathrm{H}$ NMR spectra of PBF and PEF obtained via ROP. $\left({ }^{*}\right)$ Chlororform. 

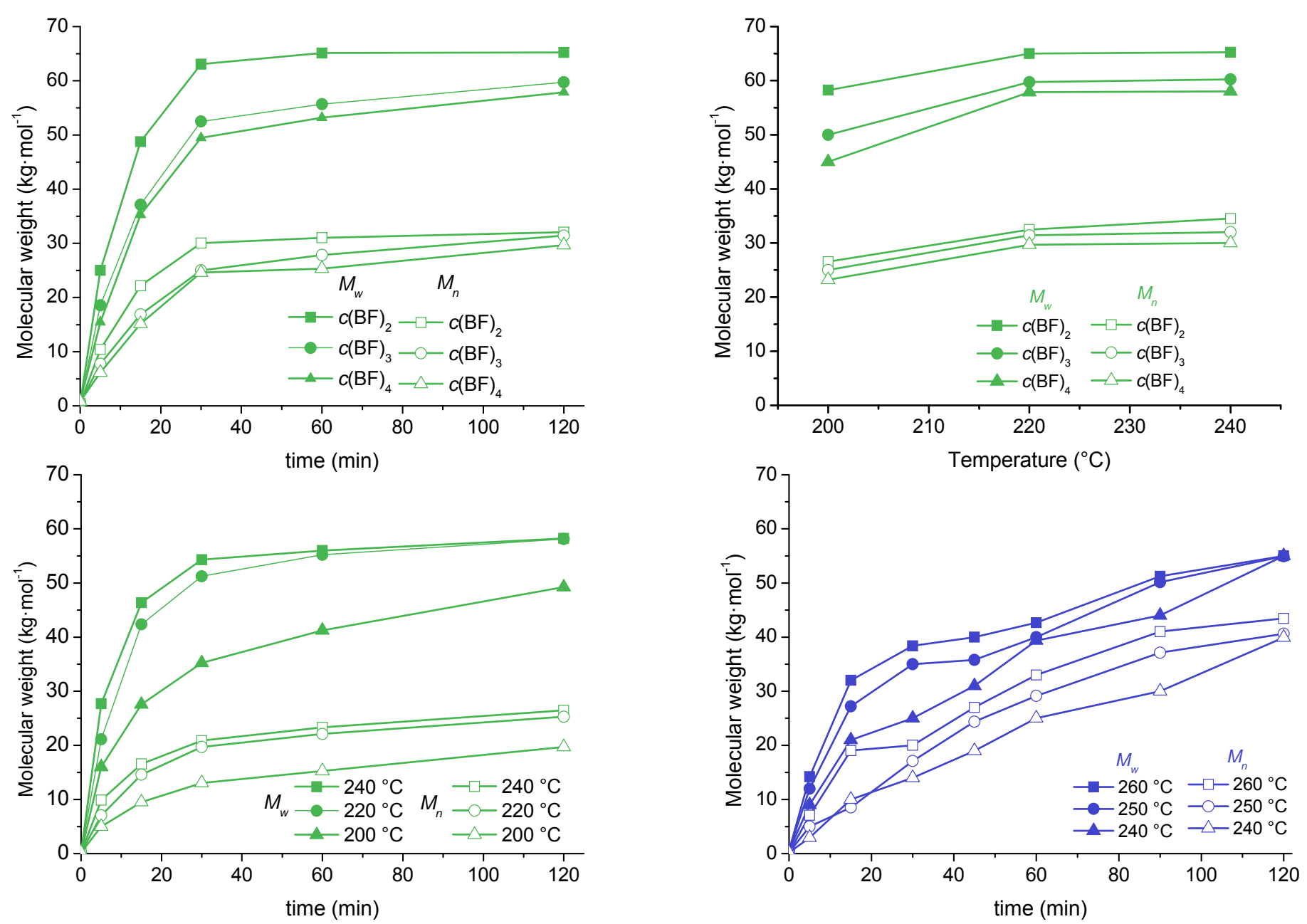

Figure 7. Evolution of molecular weight in the ROP of cyclic oligo(alkylene 2,5-furandicarboxylate)s as a function of temperature and time. Top: Compared individual cyclic oligo(butylene 2,5-furandicarboxylate)s. Bottom: Compared $c(\mathrm{BF})_{n}$ and $c(\mathrm{EF})_{n}$ mixtures for different temperatures. 

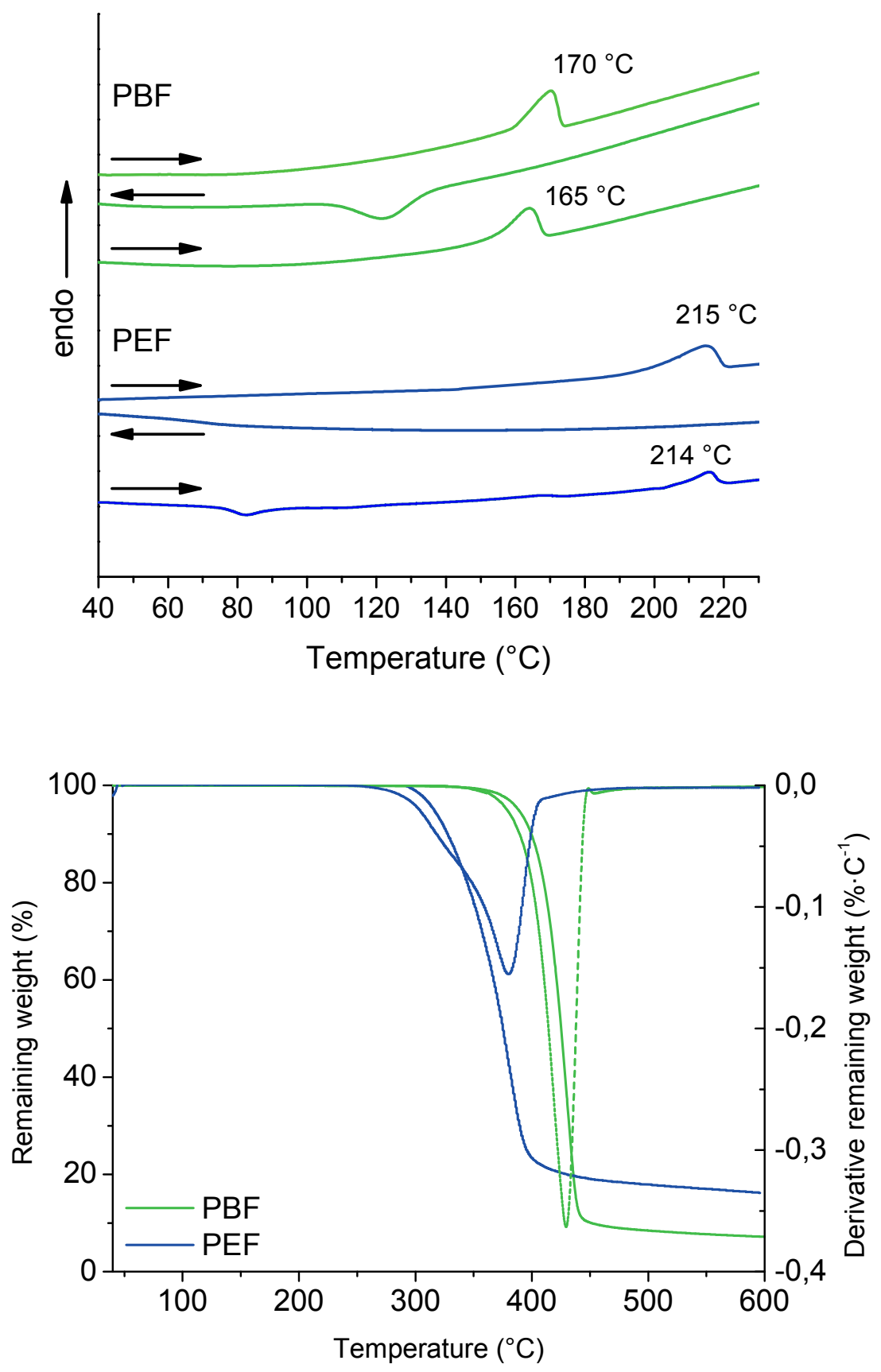

Figure 8. Top: First heating, cooling and second heating DSC traces of PBF and PEF. Bottom: TGA traces registered under inert atmosphere of PBF and PEF. 